\title{
Functioning of Information Educational Environment: Meta Dynamic Approach
}

\author{
Vera K. Vlasova ${ }^{1}$, Galia I. Kirilova ${ }^{1} \&$ Elvira G. Sabirova ${ }^{1}$ \\ ${ }^{1}$ Kazan (Volga region) Federal University, Kazan, Russia \\ Correspondence: Vera Konstantinovna Vlasova, The Institute of Psychology and Education, Kazan Federal \\ University, Kremlyovskaya Street 18, Kazan, 420008, Russia. E-mail: v2ko@mail.ru
}

Received: January 19, 2014

Accepted: February 22, 2015 Online Published: March 25, 2015

doi:10.5539/res.v7n5p25

URL: http://dx.doi.org/10.5539/res.v7n5p25

\begin{abstract}
The article substantiates the meta dynamic approach that determines ways for information educational environment analysis. The implementation of the said approach includes a versatile analysis of information with the application of offered meta dynamic methods and tools. Tools of meta dynamics allow to regard changes in the rate of the information process, to analyze structural modifications of the information environment. The change of the information process can be analyzed, for example, if the rate of new information emegence and the rate of its processing are taken into account. These and other similar measuring instruments are based on indicators of the second order. The modification of the information structure is analyzed on the basis of absolute and relative indexes of the moved and changeable information volume, and the dynamics of the environment structure. There the process of information restructuring is implied, including, for example, the emergence of new structural components, their association, removal, specification. In this context there has been given a theoretical justification for the set of meta dynamic tools of the second order application. There have been presented some results of their experimental approbation. The significance of the designated approach has a predictive value in the development of a vocational school and its information educational environment.
\end{abstract}

Keywords: meta dynamics, vocational school, educational activity, information environment, information process, information streams

\section{Introduction}

A great number of researchers describe specific aspects of information educational environment dynamics analysis, however, registration and constant analysis of information environment changes is a labor-consuming task the solution of which requires specialized knowledge in the sphere of information analytics and expert experience of the information educational environment that integrates science, production and education (Ivanov et al., 2015; Shaidullina et al., 2014, 2015; Sibgatova et al., 2015; Khairullina et al., 2015; Torkunova et al., 2014; Kirilova \& Vlasova, 2013; Masalimova et al., 2014; Biktagirova \& Valeeva, 2015).

The information educational environment, as a rule, has a heterogeneous structure that is subject to ongoing changes; some of them transform the initially accepted model of the environment described in the categories of its objects system, their leading classes and interrelations. The main issue is connected with the continuous substantial additions of information and functional potential increase of the information environment which have destructive impact on the initial ideology of this environment functioning (Mikhaylov et al., 2009). Uncontrollable changes often result in observed contradictions of common and specific objectives of environment functioning, i.e. the development of information educational environment gains a spontaneous character. The signs of spontaneity are as follows: the heterogeneity of the environment network structure; unreasonably difficult, and at times entangled and inconsistent structures; duplication and non-compliance of information in databases and knowledge; uncontrollable functioning of information streams in the interaction of information educational environment subjects in vocational training; processing, search and information analysis errors; production decrease of the applied algorithms system (Kalimullin, 2014). It is possible to expect that the improvement of the information educational environment structure will demand the creation and use of relevant tooling arrangement.

The processing of educational content is aimed to transform adequately the composition and structure of educational information in compliance with potentials and requirements of a more modern version of 
information environment (Morina, 2011; Kalimullin, 2014, 2015; Kalimullin \& Gabdilkhakov, 2014; Lisitzina et al., 2014; Masalimova et al., 2014; Ganieva et al., 2015). This refers to the choice of transformations rate which can be carried out on a full or partial scale, and to the level of integration processes in the environment which can correlate with internal or external potentials and integration requirements.

The productive evolution consists in restructuring and improvement of earlier created contents of educational information, the creation and use of new design tooling which includes: analysis tools of the established information and educational environment; means for new versions of its functionality; means to fill the environment with educational information, and means to extract information in the environment (Razinkov \& Latypov, 2007).

The singled out directions of analytical activity are described from the following positions: a) regulation of those becoming outdated, b) estimation of real ones, c) introduction of advanced components of the information educational environment. The complex analytics assumes a historically reasonable balance of information which is reflected on a time scale in categories of the period of its creation and mission: "yesterday", "today", "tomorrow" (Nurullin, 2013).

There appears to be balanced a historically reasonable, uniform transformation of information and its analysis within the frames of the experience obtained earlier, most productive modern models of information educational systems, and tools applicable for its processing in the near and long-term future.

Hence, there is offered a historically proved and forecast-focused choice of structure, composition, and functions of the active information educational environment; it leads the active information educational environment to its productive application in real educational processes. At the same time, the task of tooling implementation, aimed at the processing and analysis of a higher order information, is set and solved. The aforesaid requires to appeal to meta functions; their parameters are meta dynamic characteristics on the basis of which it becomes possible to do predictive estimations. In the present synopsis there have been given characteristics that reflect essential quantitative changes (volumes of information and changes in the environment, rate and accelerations of the corresponding information processes), and the characteristics reflecting structural quality changes (dynamics of their attributes properties of the basic set of concepts).

\section{Materials and Methods}

The empirical information that characterizes the studied information educational environment as a system phenomenon makes the basis for meta dynamic characteristics. There have been gathered and processed rather extended and various empirical data that allow to create a forecast model of the information educational environment components according to temporary and essential samples that set dynamic images of vocational school environment evolution.

On the basis of theoretic multiple data presentation and their summary statistical processing there is carried out a preliminary processing and detailed analysis of educational information presented in the information environment (Heineckea et al., 2001).

The modeling of evolutionary structures projections and subsets of information in time and space is provided on the basis of the specified dynamics.

There has been introduced a discrete scale "yesterday-today-tomorrow"; it allows to carry out the analysis from the point of view of the evolution position in time. Specific intervals of time characterize the transition duration from the past via the present to the future (Hall et al., 2012). Scaling is carried out on the basis of quantitative estimations uniformity of accumulated changes within a certain interval and quality changes of critical mass of changes for the transition to the following intervals.

\section{Results}

Let us define leading tendencies characterizing historical development of vocational training information educational environment, described in information technical and information pedagogical terms:

- The structure of technologies owned by the society is described by the set of physical, namely information technical categories;

- The distribution of a probable way to realize relevant images of forthcoming social development is described by the set of humanitarian, namely information pedagogical categories.

Information pedagogical technology will correspond to a forecast information technical system; their balance shall be specified in the context "the leader - the follower". In this case, cause-and-effect relationships have an interdependent character; it gives some meta dynamic shifts of roles in the development of the information 
educational environment that can be classified through either humanitarian deficiency, or information technical surplus. Such distortion is characterized by the prevalence of a technical component and attracts structural redundancy; the information environment can lose its system-forming properties and focus on the mankind benefit.

The reverse distortion is represented as the prevalence of information pedagogical environment aspects over environment technological potentials. Such distortion will entail essential costs connected with the search of information and as a result will decrease motivation.

The balanced development assumes: a) to provide required necessary conditions of information and pedagogical efficiency in the humanitarian and technological sphere in the context of productive thinking, b) to realize sufficient conditions of pedagogical and information efficiency in the context of design activity product creation.

First of all, we consider necessary conditions of efficiency in the humanitarian sphere from the point of view of their adequate focus on the development of a competent specialist possessing good information knowledge. Such efficiency is inseparably linked with the progress in the technical sphere, and makes itself felt through the creation of a tooling base of the information educational environment development.

There have been singled out sufficient humanitarian and pedagogical conditions of moving away from reproductive education to apply productive methods in the active educational process. Sufficient technical and information conditions include the creation of educational resources system and methodical provision aimed to develop the experience of design activity focused on the creation of a product that possesses such a quality as completeness in the set of some specific consumer properties.

Let us designate the interdependence of humanitarian and information sphere according to the following positions:

- The reliance on a strong humanitarian development provides target integrity of a personal development and competences required by the info sphere; it is provided by the choice of adequate active and productive educational technologies,

- The reliance on a strong technical pedagogical development is expressed in the application of adequate instruments for design activity that can realize the finished information product which meets accumulative potentials of the modern society and production, based on knowledge.

The fruitfulness and productivity of students' educational activity in vocational school is expressed:

- In the creation of a product as a complete useful material result, as a realized project,

- In the creation of productive technologies promoting the transition of an educational process to the use of analytical-forecast methods of activity.

- In the change of students and teachers due to the obtaining of new useful experience as a result of their joint activity, and their formation as subjects of information interaction,

- In the accumulation and improvement of standard experience that increases the level of the project implementation.

It is important that the efficiency in this context has information and technological, educational and professional aspects, and is regarded as a criterion of an adequate choice, and demands students' steady motivation and teachers' consulting activity.

\section{Discussions}

The idea that knowledge is an information product by its nature makes the basis of the offered meta dynamic approach. Thus, concepts of information streams, life cycle of information and the possibility for its repeated use without consumer properties loss are taken into account for its advance in future professional activity (Kalimullin, 2012).

The peculiarity of information streams of meta dynamic interactions is revealed not only in the complexity and volumes of used information, but also in the accounting of its innovation criteria, and its abstractness degree, which are realized at intuitive, pragmatic, and rational levels (Vlasova, 2012).

Intuitive interaction is carried out on the basis of the feeling that it is correct when new material is studied. Pragmatic interaction is based on knowledge and experience; it is typical when various educational technologies are used. Rational interaction is proved analytically and does not depend on the previous experience; it can determine the strategy of educational policy in a higher education institution. 
In real educational process, all types of interactions are involved to various extents, though, one of them predominates according to the level and stage of studies in a higher school.

General characteristics of information streams of meta dynamic interactions in vocational training are their basic functional indicators:

- The level of practice-orientation in higher education and variable orientation of educational programs of higher education institutions to meet the social order;

- Risk of graduates' unemployment and employers' expenditures for their training;

- The period of graduates' adaptation on the labor market in dynamic conditions of its development.

\section{Conclusion}

Meta dynamic interactions of information streams in the educational environment of vocational training ensure education quality steady assessment that provides: a) dynamic requirements for specialists' training from the point of view of their professional and job obligations; b) students and teachers' orientation to the efficiency of the vocational training information environment; c) correction and adaptation of education content to new conditions of the society development and processes of its dynamics.

Thus, meta dynamics of the information educational environment functioning in professional education at all its levels is expressed in the orientation of meta dynamic interactions of information streams to the maintenance of a graduates' professional qualification in a higher school as the result of its vocational training program development.

\section{Acknowledgments}

The work is performed according to the Russian Government Program of Competitive Growth of Kazan Federal University

\section{References}

Baruch, O., Ingrid, B., Joseph, L., \& Arkady, S. (2005). Can interaction content analysis research contribute to distance learning? Educational Media International, 42, 161-171. http://dx.doi.org/10.1080/09523980500060324

Biktagirova, G. F., \&. Valeeva, R. A. (2015). Formation of University Students' Readiness for Parenthood. Review of European Studies, 7(4), 93-97. http://dx.doi.org/10.5539/res.v7n4p93

Ganieva, Y. N., Sayfutdinova, G. B., Yunusova, A. B., Sadovaya, V. V., Schepkina, N. K., Scheka, N. Y., ... Salakhova, V. B. (2015). Structure and content of higher professional school lecturer education competence. Review of European Studies, 7(4), 32. http://dx.doi.org/10.5539/res.v7n4p32

Ivanov, V. G., Shaidullina, A. R., Drovnikov, A. S., Yakovlev, S. A., \& Masalimova, A. R. (2015). Regional Experience of Students' Innovative and Entrepreneurial Competence Forming. Asian Social Science, 11(1), $35-40$.

Kalimullin A. M. (2014). Improvement of teachers' qualification at kazan federal university. World Applied Sciences Journal, 4, 447-450.

Kalimullin, A. M. (2014). Stages of ecological policy development in the industrial sector of Russia in the second half of the XXth century: Historical perspective. Life Science Journal, 11(8), 492.

Kalimullin, A. M. (2015). Ecological problems of middle Volga in the second half of the XXth century: Historical and ecological analysis of leading industrial regions development. Review of European Studies, $7(1), 86$.

Kalimullin, A. M., \& Gabdilkhakov, V. F. (2014). Tutoring of pedagogical activity and new ideology of teacher training in the higher education institution. Life Science Journal, 11(11), 183-187.

Kalimullin, A. M., \& Vinogradov, V. L. (2012). Vocational guidance of school students: The state of the problem and means of its solution. Education and self-development, 6, 148-155.

Kamp, L. M., De Jong, F., \& Ravesteijn, W. (2008). Challenging e-learning: An evaluation of the STUDIO project at TU Delft. European Journal of Engineering Education, 33, 117-125. http://dx.doi.org/10.1080/03043790701746488

Khairullina, E. R., Valeyev, A. S., Valeyeva, G. K., Valeyeva, N. S., Leifa, A. V., Burdukovskaya, E. A., \& Shaidullina, A. R. (2015). Features of the Programs Applied Bachelor Degree in Secondary and Higher 
Vocational Education. Asian Social Science, 11(3), 213-217.

Kirilova, G. I., \& Vlasova, V. K. (2013). Integration potential of information environmental approach in vocational training. Philology and Culture, 31, 244-251.

Lisitzina, T. B., Pavlova, A. V., Khanmurzina, R. R., Vlasova, V. N., Chitalin, N. A., Maksimov, I. N., \& Zakirova, V. G. (2014). Features of the Professional and Motivating Training Content Design for Students Majoring in "Tourism". Asian Social Science, 11(1), 148. http://dx.doi.org/10.5539/ass.v11n1p148

Masalimova, A. R., Ikramova, G. D., Shaidullina, A. R., Gubaidullina, G. T., \& Apraksina, N. D. (2014). Distant in-company foreign language learning involving university student-tutors. American Journal of Applied Sciences, 11, 1123-1127. http://dx.doi.org/10.3844/ajassp.2014.1123.1127

Masalimova, A. R., Zakirova V. G., Chernova Y. A., Drovnikov A. S., Shaidullina A. R., \& Sakhieva, R. G. (2014). Structure and content of mentors psychological and pedagogical training curriculum. Life Science Journal, 11(7s), 381-386.

Mikhaylov, V. Y., Kirilova, G. I., \& Vlasova, V. K. (2009). Modern methods of pedagogical systems modeling. Quality. Innovations. Education, 7, 2-8.

Mikhaylov, V. Y., Volik, O. H., \& Pshenichny, P. V. (2009). About teacher's functions in the context of electronic educational resources application. Kazan pedagogical journal, 6, 89-98.

Morina, O. V. (2011). Methodical provision of self-test calculation results in the interactive environment of technical calculations. Kazan pedagogical journal, 5, 108-111.

Nurullin, R. A. (2013). Philosophic problems of correlation between professional education and education in general. Middle-east journal of scientific research, 17, 226-232.

Razinkov, E. V., \& Latypov, R. H. (2007). The hidden information transfer with the use of objects' borders. Scientific notes of Kazan university Series: Physical and mathematical sciences, 2, 128-137.

Shaidullina, A. R., Fassakhova, G. R., Valeyeva, G. K., Khasanova, G. B., Komelina, V. A., \& Ivanova, T. L. (2015). A Comparative Research on Levels of Students' Formation Skills of Their Career Advancement Portfolio in Secondary and Higher Education Systems. Asian Social Science, 11(1), 375-379.

Shaidullina, A. R., Masalimova, A. R., Vlasova, V. K., Lisitzina, T. B., Korzhanova, A. A., \& Tzekhanovich, O. M. (2014). Education, science and manufacture integration models features in continuous professional education system. Life Science Journal, 11, 478-485.

Sibgatova, K. I., Mirzagalyamova Z. N., Pupysheva E. L., Mirzanagimova F. I., Shkinderova I. N., Nuriyeva E. N., ... Schepkina N. K. (2015). The Educational Institution Teachers and Professional Community Representatives' Readiness Formation for the Joint Pupils' Career Guidance Implementation. Review of European Studies, 7(1), 74-79.

Sibgatova, K. I., Sabirov, I. T., Sadovaya, V. V., Vlasova, V. K., Leyfa, I. I., Yatsevich, L. P., \& Fassakhova, G. R. (2015). Pedagogical Potential of the Career Guidance Course "Professional Career Planning" to Form Pupils and Students' Self-Determination in the Integrated System "School—Vocational College". Review of European studies, 7(1), 80-85.

Torkunova, J. V., Khairullina, E. R., Komelina, V. A., Volkova, N. V., \& Ponomarev, K. N. (2014). The Peculiarities of Qualitative Information, Analytical Maintenance Innovative and Educational Activity Technological Projection in Higher Educational Institution. Life Science Journal, 11(8s), 498-503. Retrieved from http://www.lifesciencesite.com.108

Vasilis, G. (2012). Integrating program theory and systems-based procedures in program evaluation: A dynamic approach to evaluate educational programs. Educational Research and Evaluation: An International Journal on Theory and Practice, 18, 53-64. http://dx.doi.org/10.1080/13803611.2011.640874

Vlasova, V. K. (2010). Logistic bases of information streams management in the modern information educational environment. The Bulletin of Kazan State Power Engineering University, 2, 146-151.

Vlasova, V. K. (2012). The design of the content of education on the basis of integration of information streams. Munich, Germany.

Vlasova, V. K. (2012). The variability of information-Logistics designing of the content of teacher education. Westwood, Canada.

Vlasova, V. K., \& Kirilova, G. I. (2012). Algorithms of monitoring and control of educational process in the 
context of electronic educational resources. Quality Innovations Education, 7, 36-40.

Vlasova, V. K., \& Kirilova, G. I. (2014). Variable algorithms of information environment application in the educational process. Life Science Journal, 11, 669-673.

Vlasova, V. K., Kirilova, G. I., \& Mikhaylov, V. Y. (2009). Creation of object-oriented and logical-mathematical models of pedagogical systems. Siberian pedagogical journal, 3, 66-74.

Walter, F. H., Natalie, B. M., Lisa, A. W., \& Laura, B. (2001). New Directions in the Evaluation of the Effectiveness of Educational Technology. Computers in the Schools, 18, 97-110. http://dx.doi.org/10.1300/J025v18n02_07

Wayne, H., Stuart, P., \& Mitchell, B. (2012). A longitudinal evaluation of a project-based learning initiative in an engineering undergraduate programme. European Journal of Engineering Education, 37, 155-165. http://dx.doi.org/10.1080/03043797.2012.674489

\section{Copyrights}

Copyright for this article is retained by the author(s), with first publication rights granted to the journal. This is an open-access article distributed under the terms and conditions of the Creative Commons Attribution license (http://creativecommons.org/licenses/by/3.0/). 